\title{
Practical Teaching Platform Construction Based on Moodle-Taking "Education Technology Project Practice” as an Example
}

\author{
Ruonan Xing \\ Communication School, Jiangxi Normal University, Nanchang, China \\ Email: mary209@21cn.com
}

Received May 2013

\begin{abstract}
Moodle platform is the international popular course management system. Based on the project practice of education technology course as an example, this article has set up a platform of experimental teaching based on Moodle platform. It mainly illustrates from the course management, self-regulated learning test, to procedural evaluation and so on. This platform gives full express to the advantages of double main teaching model in which the teacher is dominant while students are the main body, and it has significance on reference to the practical and experimental curriculum.
\end{abstract}

Keywords: Moodle; Teaching Platform; Practical Teaching

\section{Introduction}

The project practice of education technology is a required course for educational technology, and it is the course that facing the educational technology professional students' comprehensive intensive training about practice project actual design and development ability. This curriculum is based on project practice form of an open laboratory environment, under the guidance of students in teacher's timing, independent practice and to complete project tasks. This article sets up an experiment aided by teaching platform based on Moodle platform, trying to improve the students' learning initiative and the ability to practice. It is hoped that the effect is obvious through teaching practice.

\section{The Experiment Teaching Current Situation}

The project practice of the education technology has been opened for more than four years in our university. Currently we adopt the task driving teaching method based on constructivism, every two to four weeks for a task, alternating between theory teaching and practice with a task for two to four weeks. Although it has obtained the certain teaching effect, it also has the following main problems.

\subsection{Lacking of Learning Initiative}

Students' initiative in the process of experimental learn- ing is not enough, as they don't preview before the experiment, lack summary practice after class, and not have a good command of experimental theory knowledge, which is bad for students to further improve the ability of courseware, film and television and web site development, etc.

\subsection{Lacking of Real Time Monitoring}

A lot of causes content need to complete after class, because it lacks of real-time monitoring of the teachers. It relies heavily on the students' autonomy. Once students haven't enough self-discipline will make teaching difficult to achieve the expected effect.

\subsection{Lacking of Practice}

For fewer experiment lessons, students lack repeated practice, failed to achieve proficiency. With the time passed, a lot of skills will be rusty.

\section{Construction of Network Experimental Teaching Platform}

Experimental teaching platform of choice network teaching breaks through the traditional teaching time and space constraints, which has become a kind of brand-new education ways and means. Along with the network technology, continues to change, Sharing, timeliness, interactivity, pertinence of network teaching growing characteristics such as rich teaching resources, network teaching has become one of the most important teaching mode in 
colleges and universities [1]. As the project practice of education technology, this practical course based on an appropriate experimental teaching platform, and it will help teachers and students interact better, conducive to the students' self-regulated learning, and then master relevant skills.

\subsection{Process Design of Experiment Teaching}

In the experiment teaching, preview before class and summary after class directly affect the effect of the experiment as well as the students master the knowledge and skills. The majority of students learning initiative are poor, however, there are a lot of students don't prepare ahead of time, can't achieve the desired effect. Preview the report was found that many are copying each other, if, check them one by one for each and number is many, set of experiments on time does not allow.

It can not only realize students prepare inspection, but improve the working efficiency Combined with the network teaching platform. Meanwhile it can solve some problems of traditional experiment teaching, for example teachers can only guide most of the students, and can't take care of poor students' learning basis for the sake of time and space. It is difficult to treat all students one-onone tutoring alone communication problem [2].

In view of the above situation, the whole experiment link for extension in time and place, the real experimental environment and the network teaching platform to complement each other, promote each other, the whole experiment is divided into three stages.

1) Before the experiment stage: The learning guide is accomplished mainly in the network teaching platform. With specific tasks as the theme, teachers release relevant experiment content and learning resources in the network teaching platform course management and resource module to, and to design the experiment before the test is used to monitor the preparation of the students; Students login before class network teaching platform for teacher to arrange the experimental task, learning related to teaching resources, design experimental procedure, understand the matters needing attention, and accept online tests at last, through testing the students practice ability is qualified in the experiment.

2) The experimental stage: It was conducted in lab, first of all, the teacher through the network teaching platform to test results to determine the experiment's list, lead the whole experiment process, supervise students complete experiment, timely feedback to the student reviews; On the experiment class, students complete the experiment, and then fill in test report and record experimental process.

3) After the experiment stage: On network teaching platform, the teacher use Moodle statistical analysis of the students' preview and test situation after class, comprehensive given to student's evaluation, reconsiders oneself in the teaching problems, also can through the network platform for further communicate with students, answer questions; Students can through the network teaching platform at any time chat, have BBS module group discussions on the problems in the experiment.

\subsection{Main Module of Experimental Teaching Platform}

Combining with the experimental process of the above mentioned, experiment teaching based on Moodle platform mainly includes the following functional modules.

1) Experiment task management: Using Moodle platform of curriculum management, resource management system with task as the theme, released subtasks implementation experiment, experiment content, experiment purpose, learning materials (documents, pictures, video, etc.) sharing, etc. It can configurate activities flexibly during the course management, BBS, test, resources, project discussion, questionnaire survey, homework, Students self-study could be easily before class and can be easily exchanged and discussed after class. Moreover, students participate in the adjustment of experiment contents, experiment teaching closer to the actual content more actively through voting and the questionnaire survey.

2) Self-regulated learning, test and summary: Providing a preview and test preparation resources for some students of learning initiative poorly, preparing and checking problem difficultly. At the same time, using the Moodle platform of automatic test system to evaluate students' preview and experiment preparation before the experiment. Only the students passed the test can enter the laboratory and complete the test, or they must be review until passing the test to obtain the status of the experiment. Students can use the BBS or panel discussion and other activities to discuss and summary the common problems in the experiment and summary, which help students to master relevant knowledge and skills better.

3) Process-based assessment in stages: We can evaluate students combined quantitative evaluation with qualitative evaluation. Experiment process in stages consists of three aspects: Prepare readiness before experiment, Experimental operation process and Experimental summary. Teachers can design good test to quantitative evaluate student's Prepare readiness before experiment. The teacher gives a qualitative evaluation on the student in the process of experiments, and then feedback to students at the same time, students can conduct mutually the experimental summary stage [3]. The Moodle test and evaluation system can help teachers realize automatic quantitatively evaluation. This reduces the teacher's work strength, and makes the evaluation more realistic. 




Figure 1. Experimental teaching platform module.

4) Learning archives management: In the Moodle platform every learner own an independent account, all of the testing process will be recorded, it is realized the electronic learning file management. Unlike the traditional experimental teaching management, These electronic files are very easy for statistical summary, it is beneficial to teachers to analyze the teaching effect, In order to adjust the experiment courses constantly, and it is also helpful for students to review their own learning content [4].

\section{Conclusion}

The experimental teaching based on Moodle platform can help teachers and students interactive communication better, and it is good for the student's self-study, mastering practical project design and technical realization methods skillfully. The construction of the experimental teaching platform based on the modern instructional and learning theory. It fully embodies the double main teaching mode: dominated by teachers, and with the stu- dents as the main body.

\section{REFERENCES}

[1] C. X. Hu, L. H. Han, J. Li and X. X. Liu, "Instructional Design for Multimedia Courseware Design and Production based on Moodle and Teacher-Led, Student-Centered Mode," China Educational Technology \& Equipment, Vol. 36, 2010.

[2] Z. J. Ma and Y. Liu, “Applied Research of Content Analysis in the Field of Interactive Online Teaching," Modern Education Technology, Vol. 9, 2010, pp. 115-118.

[3] W. Lan, "Development and Implementation of Physics Teaching Platform in MOODLE Environment," Jilin University, Changchun, 2010.

[4] J. H. Li, "Informationization Curriculum Design-Moodle-Based Informationization Learning Environment Design,” East China Normal University Press, Shanghai, 2007, p. 1. 